http://www.moderntechno.de/index.php/meit/article/view/meit09-02-020 DOI: 10.30890/2567-5273.2019-09-02-020

\title{
УДК 364
}

\section{INNOVATIONS IN THE SPHERE OF PENSION PROVISION ИННОВАЦИИ В СФЕРЕ ПЕНСИОННОГО ОБЕСПЕЧЕНИЯ}

Denisova I.P./ Денисова И.П. d.e.s., prof. / Ә.э.н., проф. Ростовский государственный экономический университет (РИНХ), Ростов-на-Дону, Б.Садовая ,69 Rostov State University of Economics(RSUE), Rostov-on-don, B. Sadovaya, 69

Myzaev V.Z./ Музаев M.3. c.e.S./ К.э.H. Управление Пенсионного фонда России, Ачхой-Мартановском район, Чеченская республика

Department of the Pension Fund of Russia, Achkhoy-Martanovsky district, Chechen Republic

\begin{abstract}
Аннотация. В статье проводятся исследования отношений по поводу формирования финансовых ресурсов пенсионной системы, иентральным звеном которой выступают источники формирования Пенсионного Фонда. Проанализирована практика финансирования сочиальных потребностей $u$ определена необходимость внедрения инновационных механизмов пенсионного обеспечения.

Показано, что в целях обеспечения финансовой устойчивости системы пенсионного обеспечения необходимо активизировать не только финансовые, но и институциональные элементы пенсионной системы с использованием циифровых технологий и методов актуарного моделирования.

Перенос процессов и механизмов формирования эффективной финансовой системь пенсионного обеспечения обеспечит устойчивое функиионирование социальноориентированной экономики.
\end{abstract}

Ключевые слова: пенсионное обеспечение, пенсионная система, бюджет, доходы и расходы Пенсионного Фонда, циифровые технологии.

\section{Вступление}

Эффективность финансового обеспечения пенсионной системы является показателем уровня жизни лиц пенсионного и предпенсионного возраста, стимулом к продолжению активной жизнедеятельности, показателем конкурентоспособности национальных стратегий социально-экономического развития.

Наиболее результативными реформами, на наш взгляд, следует считать преобразования, которые позволяют запустить механизмы, четко учитывающие такие факторы, как: средняя продолжительность жизни населения в абсолютном выражении, продолжительность жизни до и после выхода на пенсию, возраст выхода на пенсию и соотносить эти показатели с размером активов и обязательств бюджетной системы по выплате пенсий.

На преобразования пенсионной системы, повышение ее устойчивости и эффективности определяющее воздействие оказывают демографические и социально-экономические факторы: несоответствие роста зарплаты и уровня инфляции, пресс демографической нагрузки, низкая производительность труда при высокой его интенсивности.

Данные предпосылки оказывают влияние на показатели 
производительности труда, на определение затрат трудовых ресурсов в зависимости от количества трудоспособных, застрахованных и объема администрирования страховых взносов. [1].

Учет данных детерминантов возможно осуществить в рамках актуарноцифрового моделирования, преобразования источников и методов администрирования финансовых источников, трансформации институтов пенсионного обеспечения в рамках использования перераспределительных и корпоративно-накопительных принципов финансирования.

\section{Основной текст}

Социальное неудовлетворенность, связанная с сокращением размера выплат, увеличением пенсионного возраста, отказом от льгот, повышением взносов в пенсионный фонд - обратная сторона медали любой реформы, которая является существенным аргументом в пользу бюджетно распределительных механизмов.

Однако, несмотря на преимущества даже при ухудшении демографической ситуации, распределительная модель устойчива только при значительном превышении числа работающих над численностью пенсионеров.

Основной элемент национальной пенсионной системы России базируется на страховом механизме, в основе которой - распределительно-накопительная модель, при этом в разрезе распределительной составляющей пенсионной системы предусмотрено применение условно-накопительных счетов, при которых размер пенсии зависит от объема накопленных пенсионных прав.

Центральным финансово-институциональным звеном системы как пенсионного обеспечения, так и всего государственного социального страхования является Пенсионный фонд, весомую часть которого составляют выплаты различных видов пенсий в текущем году.

Существующие на данный момент формы аккумулирования пенсионных накоплений ведут к отвлечению финансовых ресурсов от выполнения текущих обязательств, о чем свидетельствуют как кассовые разрывы, так и дискуссии по поводу управления дефицитом бюджета Пенсионного Фонда РФ. Этап пенсионного пенсионной реформы, связанный с увеличением пенсионного возраста рассчитан на финансовый эффект от увеличения пенсионного возраста, однако это эффект может повысить возможные экономические и социальные риски, и усложнить методы оценки этих рисков.

Данная ситуация вызывает необходимость внедрения альтернативных механизмов и источников финансового обеспечения пенсионной системы.

Многие авторы, изучающие проблемы пенсионного обеспечение считают, что основная проблема вызывающая дискуссии в этой области -вопрос дефицита Пенсионного фонда РФ. Этот вопрос в свою очередь имеет ряд альтернативных решений:

- дифференциация индексации пенсий;

- борьба с сокрытиями заработной платы, информационное взаимодействие по раскрытию информации о самозанятых и нелегальных рабочих;

- пересмотр системы пенсионного обеспечения госслужащих с учетом 
повышения пенсионного возраста. [2]

Основными регуляторами сбалансированности доходов и расходов являются следующие факторы: размер пенсий; способы индексации; сроки изменения(повышения).

К сожалению, дефицит бюджетных средств - гораздо более частая ситуация, нежели профицит. Так дело обстоит и в большей части других стран. Обычно профицит достигается при экономической ситуации, которая близка к идеальной, что, разумеется, происходит нечасто.

Одним из методов управления дефицитом является изменения принципов и методов администрирования в системе обязательного социального страхования.

Введение единого сбора способствует созданию инструмента, с помощью которого налоговые органы смогут взять плательщиков под контроль.

Цифровая платформа Пенсионного фонда России аккумулирует цифровые социальные сервисы. С одной стороны, она должна понизить транзакционные расходы ведомства, а с другой - обеспечить активное развитие цифровизации отечественной экономики.

Функция контроля возложена на цифровые платформы Пенсионного Фонда. Цифровизация и методы актуарного моделирования меняют роль пенсионного страхования от чистой защиты от рисков к прогнозированию и предотвращению рисков.

Цифровые технологии стимулирую инновационный механизм развития финансового сектора экономики. Исследования показывают, что наиболее передовыми и перспективными финансовыми технологиями могут быть:

- «Big Data и анализ больших данных;

- Искусственный интеллект;

- Роботизация;

- Биометрические технологии снижения технологических рисков. [3].

Пенсионный фонд России планирует использовать технологию блокчейн для отслеживания информации о трудовых договорах между работодателями и сотрудниками, чтобы уменьшить свои расходы на хранение и обслуживание большого объема данных.

Технология блокчейн совсем не нужна для подтверждения аутентичности контракта. Для этого достаточно защищенной шифрованием электронной подписи.[4]

Пенсионный фонд всегда нес ответственность за сохранность данных. Однако, существуют и недостатки оцифрованного общества. Для субъектов пенсионной системы: негосударственных пенсионных фондов, страховых компаний внедрение цифровых технологий имеет ряд рисков: персональные данные, доступные страховщикам могут быть доступны и другим субъектам, что может повлиять на доверие клиентов.[5]

\section{Заключение и выводы}

Повышение пенсионного возраста вызывает много дискуссий. Существуют различные точки зрения экспертов о влиянии увеличения пенсионного возраста на уровень бедности в нашей стране (в частности, в связи с ожидаемым 
повышением уровня безработицы).

Оценка состояния бюджета пенсионного Фонда позволяет определить задачи, которые стоят перед всей пенсионной системой:

- поддержание соответствие между уровнем пенсий и заработных плат;

- упорядочение структуры пенсии, с дифференциацией на уровни финансирования;

- региональная привязка трудового стажа;

- формирование пенсионных прав и обязательств на основе актуарной сбалансированности.

В долгосрочной перспективе возможно расширение обязательных и добровольных видов краткосрочного и долгосрочного пенсионного страхования. Для этого, необходимо:

- модернизировать институциональную структуру пенсионной системы и более четко определить статус его субъектов;

- разработать комплекса мер по дальнейшему развитию дополнительного накопительного пенсионного страхования.

Требуются преобразования и в области тарифной политики, которая, как показывает практика, формируется без учета основного требования, предъявляемого к страховым пенсионным системам поддержания актуарной (текущей и долгосрочной обеспеченности) сбалансированности пенсионных обязательств и тем самым увеличивает зависимость ПФР от федерального бюджета, несущего по обязательствам Фонда субсидиарную ответственность. Данные мероприятия позволят повысить финансовую самостоятельность и устойчивость пенсионной системы.

\section{Литература}

1. Приказ Минэкономразвития России от 28.12.2018 N 748 "Об утверждении Методики расчета показателей производительности труда предприятия, отрасли, субъекта Российской Федерации и Методики расчета отдельных показателей национального проекта "Производительность труда и поддержка занятости [Электронный ресурс]. - Режим доступа: http: //www.consultant.ru/law/ (дата обращения: 05.10.2019г.).

2. Соловьев А.К. Проблемы эффективности пенсионной системы России в условиях реформы // Мир новой экономики. - 2014. № 4. -С. 39-50.

3. Основные направления развития финансовых технологий на период 2018 - 2020 годов - [Электронный ресурс]. - Режим доступа: http://www.cbr.ru/

4. Информационные технологии в Пенсионном фонде РФ. Статья. http://www.tadviser.ru/index.php/

5. Age A view on key implications for the economy and society Christian Schmidt, Director Digitalization research programme - The Geneva Association. ttps://www.genevaassociation.org/

\section{References}

1. Order of the Ministry of Economic Development of Russia dated 12.28.2018 N 748 "On approval of the Methodology for calculating labor productivity indicators of an enterprise, industry, subject of the Russian Federation and the Methodology for calculating individual indicators of the 
national project" Labor productivity and employment support [Electronic resource]. - Access mode: http: //www.consultant.ru/law/ (date of access: 05.10.2019).

2. Soloviev A.K. The problems of the effectiveness of the Russian pension system in the context of reform // World of the new economy. - 2014. No. 4. -C. 39-50.

3. The main directions of development of financial technologies for the period 2018 - 2020 [Electronic resource]. - Access mode: http://www.cbr.ru/

4. Information technology in the Pension Fund of the Russian Federation. Article. http://www.tadviser.ru/index.php/

5. Age A view on key implications for the economy and society Christian Schmidt, Director Digitalization research program - The Geneva Association. ttps: //www.genevaassociation.org/

\section{Abstract}

The article studies the relations concerning the formation of financial resources of the pension system, the Central link of which are the sources of the Pension Fund. The practice of financing social needs is analyzed and the necessity of introducing innovative mechanisms of pension provision is determined.

It is shown that in order to ensure the financial stability of the pension system, it is necessary to activate not only the financial but also the institutional elements of the pension system using digital technologies and actuarial modeling methods.

The transfer of processes and mechanisms for the formation of an effective financial pension system will ensure the sustainable functioning of a socially-oriented economy.

Key words: pension provision, pension system, budget, income and expenses of the Pension Fund, digital technologies.

Статья отправлена: 07.10.2019 г.

(C) И.П.Денисова,М.З.Музаев,2019 